\title{
Рост, структура и морфология поверхности эпитаксиальных пленок CdTe
}

\author{
(С) И.Р. Нуриев ${ }^{1}$, М.А. Мехрабова ${ }^{2, \uparrow}$, А.М. Назаров ${ }^{1}$, Р.М. Садыгов ${ }^{1}$, Н.Г. Гасанов ${ }^{3}$ \\ ${ }^{1}$ Институт фризики им. Г.М. Абдуллаева Национальной академии наук Азербайджана, \\ Az-1143, Баку, Азербайджан \\ ${ }^{2}$ Институт радиационных проблем Национальной академии наук Азербайджана, \\ Az-1143, Баку, Азербайджан \\ ${ }^{3}$ Бакинский государственный университет, \\ Az-1143, Баку, Азербайджан \\ 『E-mail: m.mehrabova@science.az, mehrabova@mail.ru \\ (Получена 28 апреля 2015 г. Принята к печати 18 мая 2016 г.)
}

\begin{abstract}
Проведено исследование структуры и морфологии поверхности эпитаксиальных пленок CdTe, выращенных на стеклянных подложках без компенсации и с компенсацией дополнительным источником паров Те в процессе роста. Определены оптимальные условия $\left(T_{\mathrm{so}}=1000-1100 \mathrm{~K}, T_{\mathrm{su}}=570-670 \mathrm{~K}\right)$ получения эпитаксиальных пленок с совершенной структурой и чистой, гладкой поверхностью, без включения второй фазы. Установлено, что на стеклянных подложках эпитаксиальные пленки растут плоскостью (111) кубической границентрированной решетки с параметром $a=6.481 \AA$.

Регулированием температуры основного и компенсирующего источников получены пленки CdTe с $n$ - и -типом проводимости.
\end{abstract}

DOI: 10.21883/FTP.2017.01.43992.7947

\section{1. Введение}

Пленки теллурида кадмия (CdTe) в последние годы привлекают внимание исследователей в связи с их перспективами в изготовлении солнечных элементов и радиационных сенсоров. Преимущество этих соединений в том, что они обладают высоким коэффициентом поглощения $\left(>10^{5} \mathrm{~cm}^{-1}\right)$ и оптимальной шириной запрещенной зоны $(>1.5$ эВ) [1-3].

Эффективность таких приборов сильно зависит от структурного совершенства пленок. Разработаны различные методы получения тонких пленок указанного соединения. В последние годы опубликовано много работ посвященных получению [4-7] и исследованию оптических и электрических свойств пленок $\mathrm{CdTe}[8-18]$. Однако комплексные исследования особенностей роста, структуры и морфологии поверхности мало проведены.

Известно, что приборы создаются в тонких приповерхностных слоях кристаллов. В связи с этим для получения высокоэффективных солнечных элементов и высокочувствительных радиационных детекторов, исследования структуры и морфологии поверхности пленок представляют научный и практический интерес.

\section{2. Эксперимент}

В настоящей работе рассматриваются исследования структуры и морфологии поверхности эпитаксиальных пленок CdTe, выращенных на стеклянных пластинах методом конденсации молекулярных пучков в вакууме $1-2 \cdot 10^{-3}$ Па. Размеры стеклянных подложек составляли $15 \times 15 \times 1$ мм. В качестве источника использовались синтезированные соединения $\mathrm{CdTe}$.
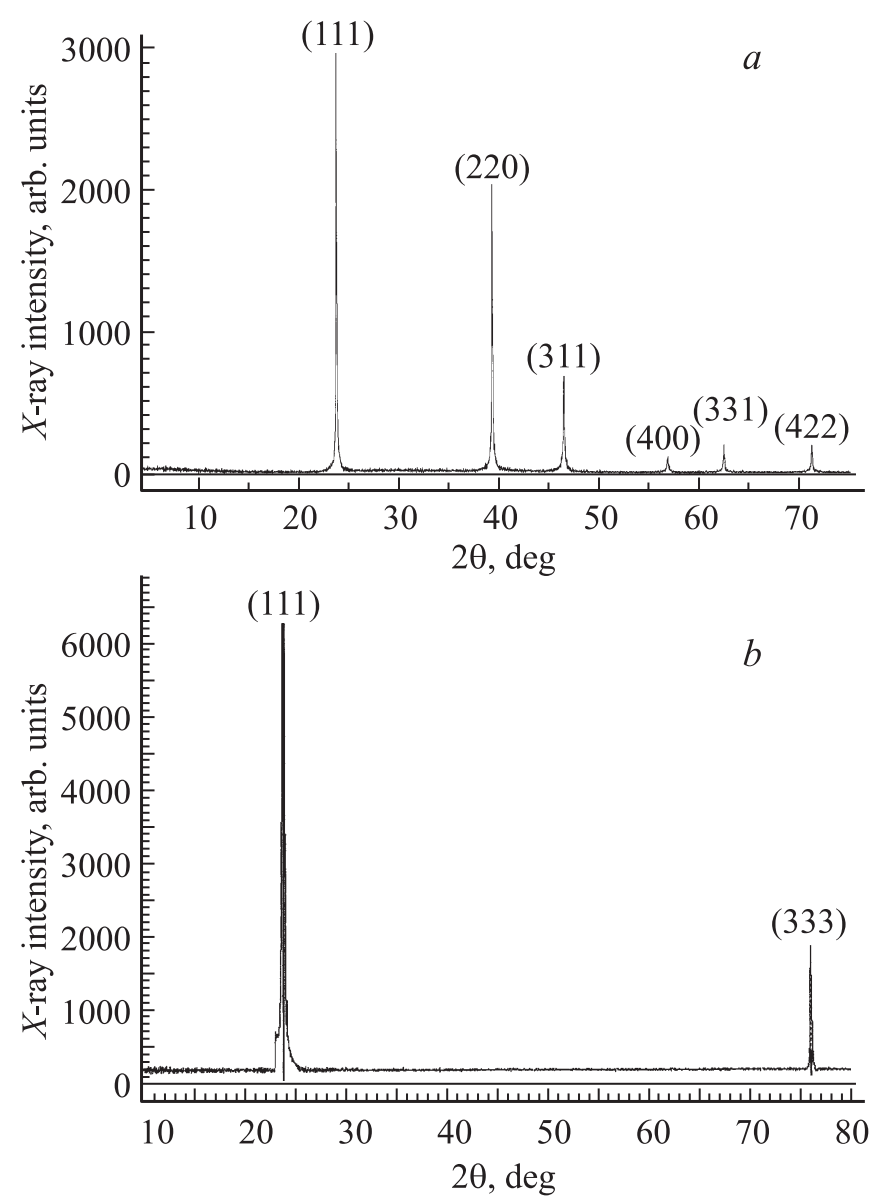

Рис. 1. Дифрактограммы пленок $\mathrm{CdTe}$, полученных на стеклянных подложках: $a$ - поликристаллическая пленка $\left(T_{\mathrm{su}}=470 \mathrm{~K}\right), b-$ эпитаксиальная монокристаллическая пленка $\left(T_{\mathrm{su}}=670 \mathrm{~K}\right)$. 
Пленки были получены в вакуумной установке УВН-71П3 при температурах подложки $T_{\mathrm{su}}=300-670 \mathrm{~K}$ с компенсацией и без компенсации паров Те в процессе роста.

Структуры пленок исследовались рентгенодифракционным методом. Дифрактограммы были получены на рентгеновской установке Bruker XRD D8 Advance.

Морфология поверхности пленок исследовалась электронно-микроскопическим методом на сканирующем электронном микроскопе (СЭМ) JEOL JSM-7600F Field Emission Scanning Electron Microscope.

Форма и структурные характеристики пленок CdTe были проанализированы с помощью атомно-силового микроскопа (ACM) „NTegra Prima“ (NTMDT). ACM широко используется для анализа особенностей микроструктуры поверхностей пленок. Этот метод дает возможность определить размеры и форму частиц, а также топографические особенности поверхности.

\section{3. Результаты и обсуждения}

Рентгенодифракционным методом показано, что на стеклянных пластинах при температуре $T_{\mathrm{su}}=300 \mathrm{~K}$ полученные пленки имеют аморфную структуру. Увеличение температуры подложки $(\geq 470 \mathrm{~K})$ приводит к
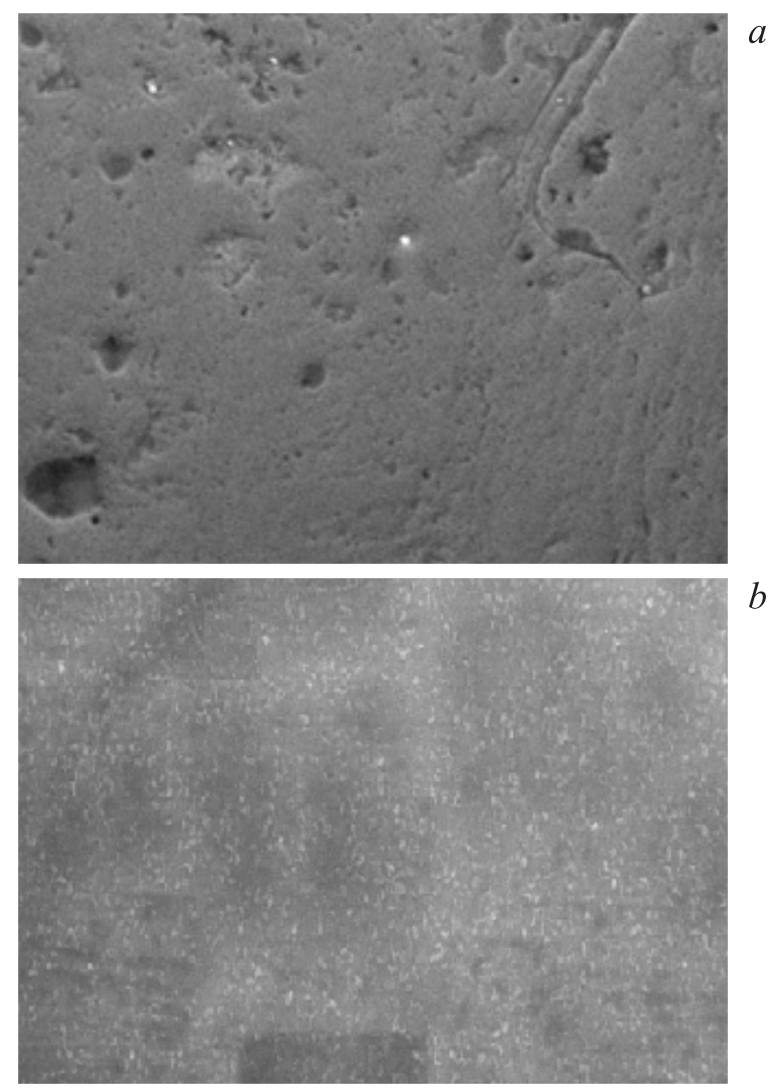

Pис. 2. Электронно-микроскопический снимок поверхности эпитаксиальных пленок CdTe: $a$ - без компенсации Те, $b-$ с компенсацией Те.
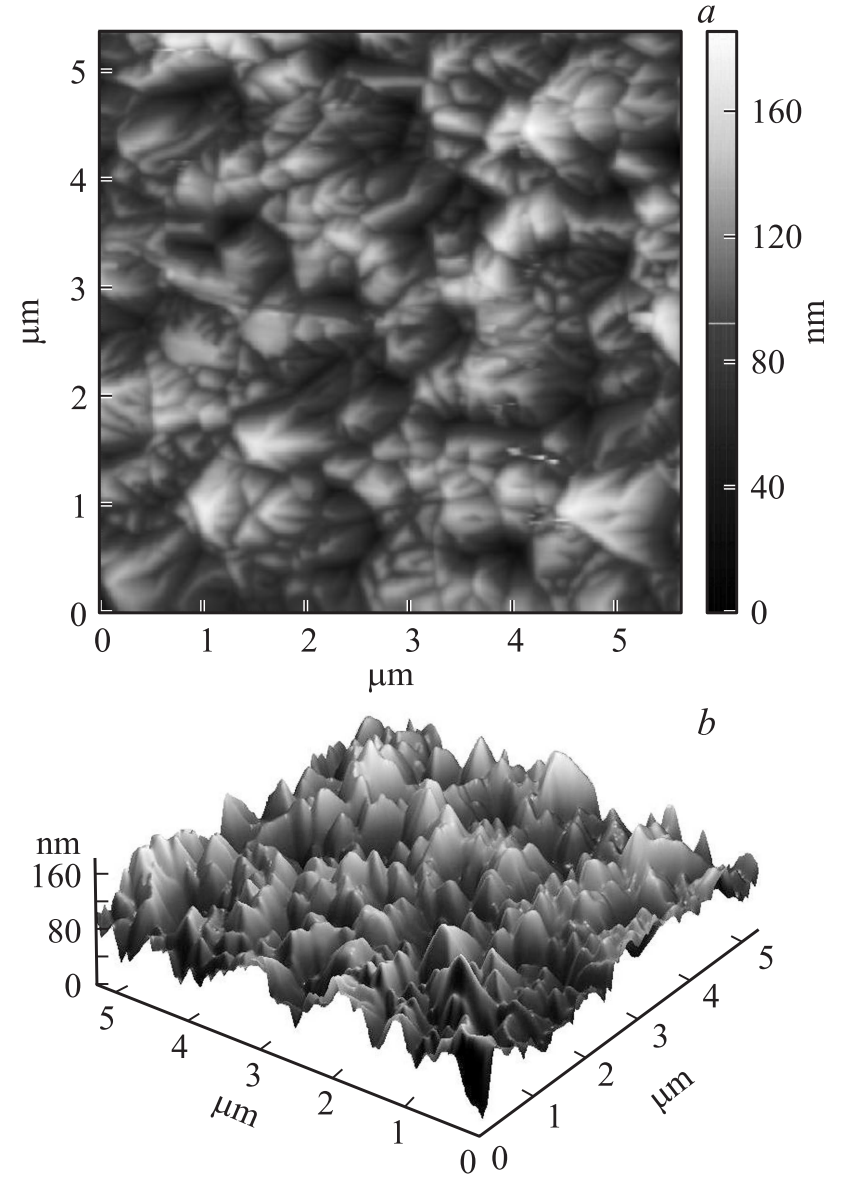

Рис. 3. АСМ-снимки пленок $\mathrm{CdTe}$ без компенсации Те: $a-2 D$-изображение, $b-3 D$-изображение.

получению поликристаллических пленок с кубической структурой $(a=6.481 \AA)$ (рис. $1, a)$. С повышением температуры выше $570 \mathrm{~K}$ начинается эпитаксиальный рост пленок и на дифрактограммах пленок, полученных при $670 \mathrm{~K}$, наблюдаются лишь отражения типа (111) (рис. $1, b$ ). Определены размеры частиц полученных пленок, которые оказались равными 122 нм.

Исследования, проводимые на СЭМ, дали возможность получить информацию о морфологии поверхности эпитаксиальных пленок CdTe, выращенных без компенсации и с компенсацией дополнительным источником паров Те в процессе роста. Сканирование проводилось с увеличением вида поверхности в 16000 раз. Результаты исследований представлены на рис. 2, $a$ и $b$. Как видно из представленных снимков, на поверхности пленок, полученных без компенсации Те, наблюдаются черные скопления, свидетельствующие об образовании продуктов окисления вследствие частичного разложения CdTe в процессе роста, которые исчезают в пленках, выращенных с компенсацией Те. В результате образуются пленки с чистой гладкой поверхностью, без включения второй фазы.

С применением АСМ получены трехмерные изображения поверхности и кривые распределения частиц по 

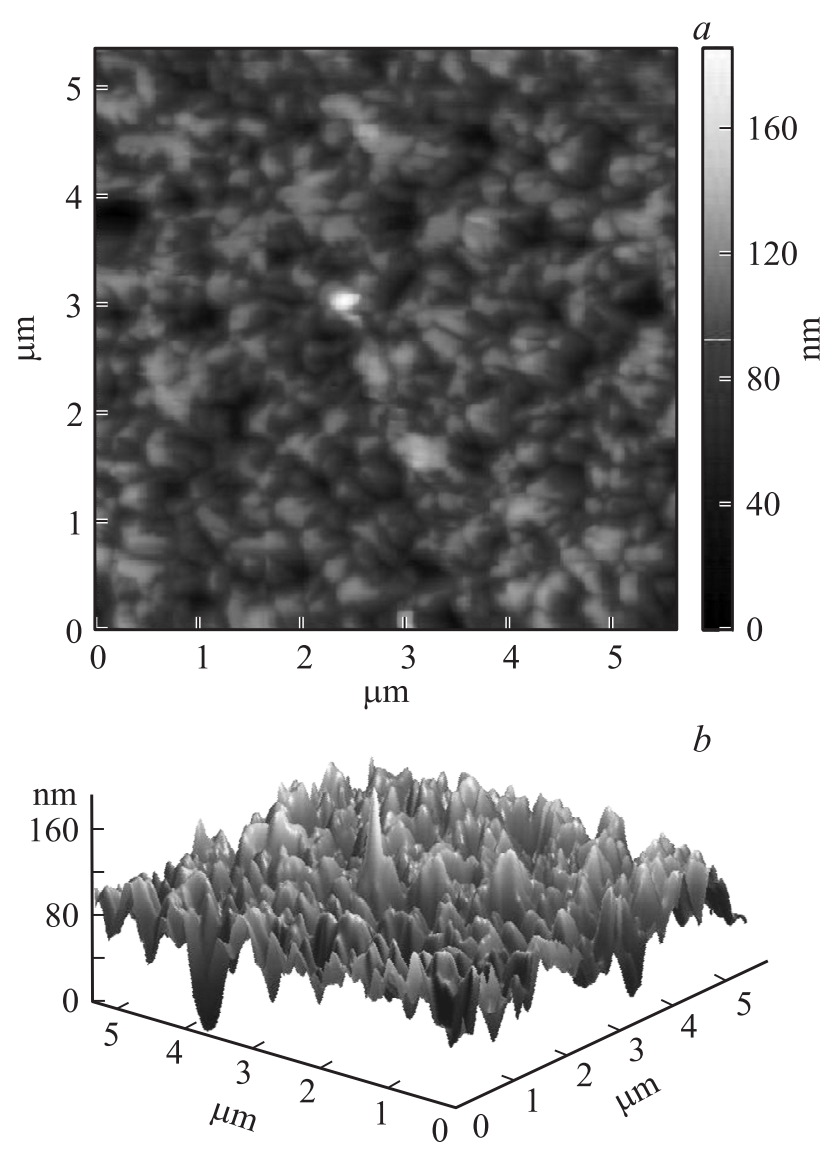

Рис. 4. АСМ-снимки пленок $\mathrm{CdTe}$ с компенсацией Те: $a-2 D$-изображение, $b-3 D$-изображение.

размерам - гистограммы, характеризующие структуры поверхности исследуемых эпитаксиальных пленок CdTe, полученных с компенсацией и без компенсации паров Те в процессе роста (рис. 3,4). Как видно из рис. 3, $a$, размеры частиц в пленке $\mathrm{CdTe}$ без компенсации Те составляют 0.14-0.7 мкм, а промежутки между частицами составляют 0.6 мкм. После компенсации Те размеры частиц составляют 0.5-1.0 мкм, а промежутки между частицами 0.5 мкм (рис. 4,a). Таким образом, после компенсации происходит улучшение структуры, т.е. размеры частиц увеличиваются, шероховатости уменьшаются. Из $3 D$-изображений (рис. $3, b, 4, b$ ) и гистограмм определили распределения высот частиц, максимальное значение которых составляло $\sim 122 \mathrm{Hм}$, что совпадает с результатами рентгендифрактометрических исследований. $2 D$ - и $3 D$-изображения показывают, что пленки, полученные с компенсацией Те, имеют более совершенную структуру.

\section{4. Заключение}

С применением метода конденсации молекулярных пучков выращены структурно совершенные эпитаксиальные пленки CdTe на стеклянных подложках. Определены оптимальные условия получения $\left(T_{\mathrm{so}}=1000-1100 \mathrm{~K}\right.$, $\left.T_{\mathrm{su}}=570-670 \mathrm{~K}\right)$ эпитаксиальных пленок. Пленки имеют кубическую гранецентрированную структуру с параметром решетки $a=6.481 \AA$ и растут плоскостью (111).

Эпитаксиальные пленки, полученные с компенсацией дополнительным источником паров Те, во время роста имеют более совершенную структуру.

Работа выполнена при финансовой поддержке Фонда науки Азербайджанской государственной нефтяной компании (SOCAR), 2013.

\section{Список литературы}

[1] I.M. Dharmadasa, P.A. Bingham, O.K. Echendu, H.I. Salim, T. Druffel, R. Dharmadasa, G.U. Sumanasekera, R.R. Dharmasena, M.B. Dergacheva, K.A. Mit, K.A. Urazov, L. Bowen, M. Walls, A. Abbas. Coatings, 4, 380, (2014).

[2] В.В. Брус, М.Н. Солован, Э.В. Майструк, И.П. Козлярский, П.Д. Марьянчук, К.С. Ульяницкий, J. Rappich. ФТТ, 56 (10), 1886 (2014).

[3] Y. Cui, A. Bolotnikov, A. Hossain, G. Camarda, A. Mycielski, G. Yang, D. Kochanowska, M. Witkowska-Baran, R.B. James. Brookhaven National Laboratory (2008), www.bnl.gov/isd/documents/43404.pdf.

[4] I. Salaoru, P.A. Buffat, D. Laub, A. Amariei, N. Apetroaet, M. Rusu. J. Optoelectron. Adv. Mater., 8 (3), 936 (2006).

[5] R. Zhang, I. Bhat. J. Electron. Mater., 30 (11), 1370 (2001).

[6] M.M. Al-Jassim, Y. Yan, H.R. Moutinbo, M.J. Romero, D.R. Dhere, K.M. Jones. Thin Solid Films, 387, 246 (2001).

[7] G.V. Beketov. Proc. SPIE, 3880, 448 (1999).

[8] T.L. Chu, S.S. Chu. Sol. St. Electron., 38, 533 (1995).

[9] H.R. Moutinho, F.S. Hasoon, F. Abulfotuh, L.L. Kazmerski. J. Vac. Sci. Technol. A, 13, 2877 (1995).

[10] S. Chandra, S. Tripura Sundari, G. Raghavan, A.K. Tyagi. J. Phys. D, 36, 2121 (2003).

[11] A. Gupta, V. Parikh, A.D. Compaan. Solar Energy Mater. Solar Cells, 90, 2263 (2003).

[12] A. Azan, A.S. Ahmed, M. Charman, A.H. Naqvi. J. Appl. Phys., 108, 094329 (2010).

[13] V.V. Brus, M.I. Ilashchuk, Z.D. Kovalyuk, P.D. Maryanchuk, K.S. Ulyanytsky. Semicond. Sci. Technol., 26, 125006 (2011).

[14] V.V. Brus. Solar Energy, 86, 1600 (2012).

[15] В.В. Брус, З.Д. Ковалюк, П.Д. Марьянчук. ЖТФ, 82 (8), 110 (2012).

[16] М.Н. Солован, В.В. Брус, П.Д. Марьянчук. ФТП, 47, 1185 (2013).

[17] М.Н. Солован, В.В. Брус, П.Д. Марьянчук. ФТП, 48, 232 (2014).

[18] M.A. Mehrabova, H.R. Nuriyev, T.B. Taghiyev, R.M. Sadigov, A.M. Nazarov, N.I. Huseynov. Int. J. Mater. Sci. Appl., 3 (6-1), 20 (2014).

Редактор Г.А. Оганесян 


\section{Growth, structure and morphology of the surface of CdTe epitaxial films}

I.R. Nuriyev' ${ }^{1}$, M.A. Mehrabova ${ }^{2}$, A.M. Nazarov', R.M. Sadigov' ${ }^{1}$, N.H. Hasanov ${ }^{3}$

${ }^{1}$ Abdullayev Physics Institute of Azerbaijan National Academy of Sciences,

Az-1143, Baku, Azerbaijan

2 Institute of Radiation Problems of Azerbaijan National Academy of Sciences,

Az-1143, Baku, Azerbaijan

${ }^{3}$ Baku State University,

Az-1143, Baku, Azerbaijan

Abstract It has been carried out the study of structure and morphology of surface of CdTe epitaxial films, grown on glass substrates without compensation and with compensation of additional Te vapor source within growth process. Optimal conditions $\left(T_{\mathrm{so}}=1000-1100 \mathrm{~K}, T_{\mathrm{su}}=570-670 \mathrm{~K}\right)$ have been determined for obtaining epitaxial films with a perfect structure and clean smooth surface, without including the second stage. It is established that the epitaxial films grow on glass substrates by (111) plane of cubic face-centered lattice with parameter $a=6.481 \AA$.

Adjusting the temperature of the main and compensating sources, it has been obtained CdTe films with $n$ - and $p$-type conductivity. 